$\begin{array}{ll} & \text { Preprints are preliminary reports that have not undergone peer review. } \\ \text { Research Square } & \text { They should not be considered conclusive, used to inform clinical practice, } \\ \text { or referenced by the media as validated information. }\end{array}$

\title{
Distribution and correlation of methicillin-resistant coagulase-positive staphylococci (MRCoPS) between environmental surfaces, veterinary staff and dogs within a veterinary teaching hospital, Thailand
}

Punpichaya Fungwithaya

Walailak University

Jayaseelan Murugaiyan

FUB and SRM University

Nuvee Prapasarakul ( $\square$ Nuvee.P@chula.ac.th )

Chulalongkorn University

\section{Research Article}

Keywords: Coagulase-positive staphylococci, Dogs, Methicillin-resistant coagulase-positive staphylococci, veterinary hospitals

Posted Date: March 1st, 2021

DOI: https://doi.org/10.21203/rs.3.rs-244889/v1

License: (c) (i) This work is licensed under a Creative Commons Attribution 4.0 International License. Read Full License 


\section{Abstract \\ Background}

Coagulase-positive staphylococci (CoPS), a gram-positive cocci bacterium, is a group of bacteria causing dermatitis and septicemia in animal. Methicillin-resistant (MR) CoPS (MRCoPS) can find on human, animal and environmental including medical equipment leading to nosocomial infection. This study aimed to determine the distribution and to analyse correlation of methicillin-resistant coagulase-positive staphylococci (MRCoPS) between environmental surfaces, veterinary staff, and dogs within a Veterinary Teaching Hospital (VTH) at Chulalongkorn University (CU) in Bangkok, Thailand. All isolates were characterized the antimicrobial susceptibilities, Staphylococcal cassette mec (SCCmec) typing and clone typing by Pulsed-Field Gel Electrophoresis (PFGE).

\section{Results}

In total, 88 CoPS isolates were obtained from 53 samples comprising 24 parts of floors ( $24 / 53,45.3 \%), 14$ items of medical instruments $(14 / 53,26.4 \%), 14$ dogs $(14 / 53,26.4 \%)$ and a veterinarian $(1 / 53,1.9 \%)$. Sixty-two of 88 were MRCoPS locating in the five hospital rooms. The highest MRCoPS species were MR Staphylococcus pseudointermedius (MRSP) isolates $(57 / 62,91.9 \%)$ retrieved from 26 samples and mainly discovered on the floors. Seven antibiogram patterns and two SCCmec types were resolved from 62 MRCoPS isolates. Most of the MRCoPS (93.6\%) were resistant to at least three antibiotics. All MR Staphylococcus schleiferi subsp. coagulans (MRSSc) isolates displayed a triple antibiogram associated with the SCCmec type V, while the MRSP isolates showed various antibiograms and $\mathrm{SCC} m e c$ types. The $S$. pseudintermedius in dogs and three rooms were related by their PFGE pattern A. The average percentage of MRCoPS-positive surfaces were typically high on the floors $(20 \%)$. The dermatological room showed the highest of MRCoPS-positive surfaces on both the floor and medical instruments.

\section{Conclusions}

The distribution of CoPS and MRCoPS has become a relative common situation in veterinary hospitals, and so attention must be paid to limit cross-contamination between patients and the hospital environment. To general; please provide impact of this study digested as a take home message.

\section{Background}

Coagulase-positive Staphylococci (CoPS) are a group of Gram-positive cocci that cause dermatitis and septicaemia $[1,2]$ The three significant CoPS members in animals are Staphylococcus (S.) aureus, S. pseudintermedius, and $S$. schleiferi subsp. coagulans [3, 4]. Of importance is that canine CoPS can exchange the mobile genetic element "Staphylococcal cassette mec (SCCmec)" in both intra- and inter-species [5]. This mobile genetic element can carry many antibiotic resistance genes, especially the mecA gene (oxacillin resistant gene). Methicillin-resistant (MR) CoPS carry the $m e c A$ gene and are some of the most dangerous bacteria in human and veterinary hospitals [6, 7]. This group of pathogens can be transmittable among human, animal, and environmental surfaces, including medical equipment. Typically, MR S. aureus (MRSA) is located at a low population level in veterinary hospitals and on small animal skin but can cause pathogen outbreaks, such as that at an equine hospital. Importantly, they cause infections and septicemia in humans $[8,9]$. 
The MR S. pseudintermedius (MRSP) commonly presents multidrug resistance to certain particular antibiotic groups, such as $\beta$-lactam, macrolide, lincosamide, fluoroquinolone, and aminoglycoside [2]. Recently, the increasing distribution of MRSP in veterinary hospitals has become a high risk of surgical site infections and septicemia in animal patients and also a threat of organisation development and standardisation [10].

The distribution of MRSP in a veterinary hospital poses the risk of nosocomial infections [11-13]. Environmental surfaces, veterinary staff, and animal patients all play a role in both MRSP and (MRSSc) circulation in veterinary hospitals $[11,12,14]$. The surveillance of MRCoPS is essential in allowing the prediction of the distribution of these pathogens in hospitals [15]. MRSP has been discovered in veterinary hospitals on medical instruments, such as weight scales, examination tables, and stethoscopes [16]. The remaining MRSP in the environment is a potential cause for cross-contamination in veterinary hospitals [11]. Previously, an explosion caused by the MRSP ST71 isolate was of concern in a Finnish veterinary teaching hospital (VTH) [11]. In Thailand, veterinarians and pet owners can receive MRSP from pet and become a significant carrier sharing to medical devices. However, the factors affecting MRSP distribution were different in each hospital upon hygienic management $[11,17]$.

A suitable hygienic strategy and hospital accreditation should be suggested to control bacterial distribution in veterinary hospitals $[8,15]$, including hand hygiene, protective gear, and type of disinfectants [11]. However, there is no reported information on MRSP distribution in hospital environments related to the managements.

This study aimed to determine the distribution and correlation of MRCoPS among environmental surfaces, veterinary staff, and dogs within a Veterinary Teaching Hospital in Bangkok, Thailand and to characterise the clonal types and their antimicrobial susceptibilities and resistant gene cassette.

\section{Results}

\section{Distribution of CoPS and MRCoPS in the VTH-CU}

A total of 253 samples were collected from 216 places of environment (8 units, 5 points of floor per room and twice collection per day), 23 veterinary staff, and 14 dog patients. In total, 88 CoPS isolates were found from 53 samples comprised of 24 parts of the floors (24/53, 45.3\%), 14 medical instruments (14/53, 26.4\%), 14 dogs (14/53, 26.4\%) and one veterinarian $(1 / 53,1.9 \%)$. All rooms presented CoPS, especially the dermatological $(27.3 \%)$ and gynaecology $(22.7 \%)$ rooms. However, no CoPS were found in any disinfectant water in forceps jars, stethoscopes, branches and drug cabinets. Approximately 53\% of the CoPS were found on floors. We found the three major canine CoPS in this study, with $S$. pseudintermedius having the highest population at 75 isolates, while $S$. schleiferi subsp. coagulans presented 12 isolates, and $S$. aureus was only obtained from a veterinarian and defined as a methicillin-susceptible (MS) S. aureus (MSSA).

This population of MSCoPS was about 2.5-fold higher than that of MRCoPS. The distribution of MSCoPS and MRCoPS on the floor and medical instruments is summarised in Table 2. A total of $41 \mathrm{MRCoPS}$ samples were discovered in five hospital units: gynecology, internal medicine, post-surgery care, ICU, and dermatological room. The results divided as 16 floor sites (16/41, 39.0\%), 10 surgical items (10/41, 24.4\%), 14 dogs (14/41, 34.2\%), and one veterinarian (1/41, 2.43\%). The most common MRCoPS (62 isolates) were MRSP isolates (57/62, 91.9\%), retrieved from 26 samples and mostly present on the floors within 8 units in the hospital. Interestingly, both MRSP and MRSSc were discovered on un-used cotton in the gynaecology room.

\section{Antibiogram and SCCmectypes of the MRCoPS}


A total of 62 MRCoPS were characterised by their antibiogram using six common antibiotics used in veterinary hospitals. Only the SCCmectype $\mathrm{V}$ was detected in these samples. The percentile of resistant antibiotic drugs is displayed in Figure 1, whereas the SCCmec type is included in Figures 2-4. Overall, seven antibiogram patterns and two SCC mec types were resolved from the 62 MRCoPS isolates. All MRCoPS were resistant to clindamycin (DA), and erythromycin (E), and most (93.6\%) of the MRCoPS were resistant to at least three of the screened antibiotics with half of them having the same antibiogram patterns (CN-E-DA). All the MRSSc isolates were resistant to three antibiotics (CN-E-DA) associated with the SCCmec type V, while MRSP showed various antibiogram patterns and SCCmec types.

\section{PFGE types}

All S. pseudintermedius and S. schleiferi subsp. coagulans were identified by PFGE patterns (Figures 2-4). After cfr9l cutting, S. schleiferi subsp. coagulans showed only two patterns (A and B), while S. pseudintermedius displayed 14 patterns $(A-N)$. The relationship among $S$. pseudintermedius in the dogs and the post-surgery care, dermatological, and gynaecology rooms mainly presented the pattern A. Only $12 \mathrm{~S}$. pseudintermedius isolates could be cut by Apal only. From the Apa/ restriction enzyme pattern, the DNA fingerprints were divided into three patterns that show a close relationship between the gynaecology, post-surgery care, and internal medical rooms.

\section{Distribution of MRCoPS in the VTH-CU}

All MRCoPS were separated into two origins (floor and medical instruments) from eight VTH-CU places (Table 3). Amoxicillin/clavulanic acid and $\mathrm{E}$ were the main antibiotics used in this hospital. The common routine for floor cleaning in the six rooms was to use a mop with a $2.5 \%(\mathrm{w} / \mathrm{v})$ quaternary ammonium compound, twice daily. The dermatological room was the only room where the floor was cleaned with a broom, and this was once daily. The vaccination room was free from MRCoPS-positive places on both the floors and medical instruments. The average percentage of MRCoPS-positive surfaces were typically high on the floors (20\%) compared to the medical devices (7.7\%). In this study, the internal medicine room was chosen as the reference room due to its having the lowest MRCoPS-positive surfaces on both the floors and medical instruments. The dermatological room showed the highest of MRCoPS-positive surfaces for both the floor and medical devices.

\section{Discussion}

CoPS and MRCoPS were tentatively enumerated and isolated from medical instruments and floors in each hospital room. A high prevalence of MRCoPS, especially MRSP, was detected on the floors and medical devices in each room. The possible source of MRSP could be identified, which can then lead to preventive and control measures in the VTHCU. This cross-sectional study collected samples from environmental items, comprised of hand-touch sites, medical devices and materials, floor surfaces, veterinary staff, and dog patients in the VTH-CU, located in Bangkok's central area with a high customer flow rate (approximately 389 cases per day). The hospital has an increased risk of MRCoPS distribution and serves as a good model for study. Interestingly, the highest CoPS and MRCoPS levels were found in the dermatological room, especially on the floor and medical instruments.

One veterinarian carried MRSP with multidrug resistance in his nasal cavities. Human-contained MRSP in the nasal carriage is uncommon but closely associated with pet owners and veterinary staff [18]. Human carriers' prevalence has been reported to range from $1-5 \%$, but the highest prevalence (8\%) was reported in Thailand [18, 19]. However, it can't be concluded that dogs and all high-touch sites in the VTH-CU were the potential sources of transmission, since the human strains were not linked to those of the dogs and environmental sources. The exposure time and host 
status may be significant factors in MRSP transmission [20, 21]. However, many human-associated animal pair strains should be recruited and analysed in a further study.

In veterinary hospitals, antimicrobials are mostly administrated to the pets, leading to resistant commensal microbes on the skin [22]. This study showed that all dog patients contained CoPS on their nasal cavities, but only a few dogs harboured resistant pathogens. Nevertheless, the DNA fingerprint pattern (PFGE pattern A) showed the relationship between the MRSP clones and dogs' environment. It is possible that sharing of MRSP might occur in a veterinary hospital. A correlation between the PFGE patterns in the surgery room has been reported previously [10], but no correlation between the equipment and dog patients was found. However, this study showed the relationship between dogs and the environment in other hospital rooms. We assumed that MRSP contamination might be due to accidental sharing between dogs visiting the hospital. With prolonged use of antimicrobial administration to the dog patients, the clinical room had the highest risk of MRSP existence and maybe the potential source of the hospital distribution [23].

Most of the strains were untypable for SCCmec using the previous recommendation. The untypable SCCmec was previously identified as $\Psi$ SCC mec57395, which showed multidrug resistance that was the majority in Thailand [22]. The frequency of specific MRSP clones in an individual could be explained by selective pressure exerted by preexisting resistant strains during antimicrobial exposure. Besides, transmission of SCCmec between Staphylococcus $s p p$. is of concern in many veterinary hospitals because this mobile genetic element can carry many resistance genes in its cassette. This study showed that at least two common veterinary drugs might not be useful for CoPS infections in the VTH-CU.

Moreover, we discovered Mupirocin (MUP)-resistant bacteria in one dog. Mupirocin is not a commonly used antibiotic in veterinary treatment, but it is often used in multidrug-resistant bacterial infection cases. This drug is recommended in human treatment more than in animal treatment. Thus, MUP-resistant bacteria are of great concern in human and animal hospitals $[24,25]$.

The restriction enzymes crf9l, apal, and sac/l were previously recommended for cutting the DNA of MRSA ST 398 [26]. However, in this study, 12 S. pseudintermedius isolates could not be defined by the Crf9/based method. The apal restriction enzyme, recently used for MRSA Sequence Type 398 [27], was found to cut these 12 isolates to obtain the DNA fingerprint patterns. Given that this enzyme can cut at the methylated restriction site that Cfr9/and Sma/cannot [27], then these 12 S. pseudintermedius isolates in this study might contain methylated restriction sites. However, next-generation sequencing in a further investigation could declare their whole genome in the future.

The floor of the VTH-CU was the most frequently found area for bacterial contamination. The use of a proper disinfectant and cleaning protocol could restrict the distribution of pathogens in hospitals and reduce the prevalence of nosocomial infections $[28,29]$. However, this study provides a shred of important evidence for revising the bacterial decontamination protocol in future hospital strategic programs. Mopping with a proper disinfectant [i.e. sodium hypochlorite, $2 \%(\mathrm{v} / \mathrm{v})$ phenolic solution and $0.5 \%(\mathrm{v} / \mathrm{v})$ chlorhexidine] has been recommended as a routine cleaning protocol in a veterinary hospital [28]. In the mopping method, the disinfectant has to contact the floor surface for at least $20 \mathrm{~min}$, and then the mopping should be repeated. Additionally, we recommend changing the mop bucket twice daily: at the beginning of the day and the day's final mopping.

After routine cleaning, MRCoPS was found at the highest level in five units. In the VTH-CU, examination tables were cleaned immediately when the items were not in use. Even if the cleaning patterns were the same, residual MRSP were still found on the examination table of the gynaecology, post-surgery care, ICU, and dermatological rooms. 
Therefore, we suggest that the residual MRSP on some examination tables might result from cleaning practices and an insufficient exposure time to the disinfectant. Accordingly, we recommended revising the cleaning management to follow that of Portner and Johnson [2010]. Hand hygiene and appropriate disinfectant are recommended to control contamination on the examination tables. Concerning hand hygiene, the WHO recommended strict hand hygiene with alcohol and $0.5 \%(\mathrm{w} / \mathrm{v})$ chlorhexidine [30], while for a low contact time (5 min), a peroxygen compound, is suitable to clean the examination table.

\section{Conclusions}

In conclusion, distribution and correlation of CoPS and MRCoPS between the environmental surfaces, veterinary staff, and dogs within the VTH-CU in 2014-2016 were described. It is noteworthy that CoPS were discovered all around the VTH-CU, and some of them acted as antibiotic-resistant pathogens. The suitable sanitation, cleaning management, and annual monitoring must be practised to protect against this bacteria's distribution.

\section{Methods}

\section{Study design and ethic}

A cross-sectional study was performed at the VTH-CU, the Small Animal Teaching Hospital of the Faculty of Veterinary Science. The samples were collected during May 2014-2016. Study was approved by Institutional Animal Care and Use Committee (113/56), Faculty of veterinary science, Chulalongkorn university and the Ethical Review Committee for Research Involving Human Research Subjects, Health Science Group, CU (137/57), Research and innovation for society, Chulalongkorn University. All methods were performed in accordance with relevant guidelines and regulations.

\section{The hospital setting}

The VTH-CU is the primary veterinary hospital in Bangkok, Thailand, with approximately 140,000 patient visits each year. The hospital comprises five divisions: Emergency and Intensive Care, General Medicine, Surgical, Gynecological, and Special Rooms (Cardiology, Kidney \& Urine care, Diabetes, Dermatological, Cancer, Feline disease, and Neurological).

In 2014, approximately 389 pet patients per day visited the VTH-CU, divided as 96, 30, 27, and eight at the general medicine, gynaecological, dermatological, and surgical rooms, respectively. The routine of cleaning management in the VTH-CU was comprised as follows. The floors were washed with $2.5 \%(\mathrm{w} / \mathrm{v})$ quaternary ammonium compound (UMONIUM38 ${ }^{\circledR}$; Laboratoire Huckert's International, Thailand) between 3.30-4.00 PM. The examination tables, stethoscopes, syringe plates, waiting branch, drug cabinet, keyboard, and knot door were cleaned with $0.5 \%(\mathrm{w} / \mathrm{v})$ UMONIUM $38^{\circledR}$ when the items were not in use. The cotton for wound dressing did not change rooms when empty. The disinfectant water in forceps jars, which is $1 \%(\mathrm{w} / \mathrm{v})$ povidone-iodine (Betadine ${ }^{\circledR}$ solution; Pathumthani, Thailand), was changed every day in all rooms.

\section{Populations and sample collections}

\section{Environmental samples}

A total of 216 samples were retrieved from the environmental surfaces in nine parts of the VTH-CU; the division of general medicine $(M)$, vaccination room $(V)$, gynaecology $(G)$, dermatology $(S W)$, surgery $(S)$, post-surgery care $(P)$, 
intensive care unit (ICU), and hallway (lower and upper; H). On the sample collection day, the medicine, vaccination, and dermatological rooms were located in the new building of the VTH-CU. The gynaecology, surgery, post-surgery care, and hallways were in parts of the old building. The criteria of sample collections are described in Table 1 . The requirements for room selection were (i) having at least eight pet patients per day and (ii) the room was cleaned at least once per day. One environmental sample was collected two times within the same day; before clinics opened at 7.30-8.00 AM and after the clinics had been cleaned at 3.30-4.00 PM. In each room, samples were collected from five parts of the floor [31] at the central examination room. In the case of medical instruments, if there was more than one item in that room, then the most used item was chosen for sampling [32]. All surfaces were sampled using sterile cotton swabs. The cotton was dipped into $2 \mathrm{~mL}$ of peptone saline dilution (PSD; $100 \mathrm{mg} / \mathrm{mL}$ peptone and 850 $\mathrm{mg} / \mathrm{mL}$ sodium chloride in distilled water). The moistened swab was rolled on the surface, the cotton part cut off into the same tube and kept on ice until cultured.

\section{Veterinary staff samples}

Before this experiment started, the written informed consent was obtained from veterinary staff. Study in human was approved by the Ethical Review Committee for Research Involving Human Research Subjects, Health Science Group, CU (137/57), Research and innovation for society, Chulalongkorn University. Samples from veterinary staff were taken from one veterinary nurse per unit and 16 veterinarians who had worked more than $40 \mathrm{~h} /$ week at the VTH-CU for two years. Note that routinely, veterinarians and other staff wear a protective mask during working hours. They were asked to provide a sterile cotton swab wipe from their nasal cavities [18]. The sterile cotton swabs were dipped into $2 \mathrm{~mL}$ of peptone saline diluent (PSD) in a sterile test tube (No. 9820, Cole-Parmer ${ }^{\circledR}$, Thailand) before nasal sampling [18]. After sampling, the cotton part was cut into the same tube, contained on ice and cultured within $2 \mathrm{~h}$.

\section{Dog samples}

Before this experiment started, the written informed consent was obtained from dog owners. Study in animal was approved by Institutional Animal Care and Use Committee (113/56), Faculty of veterinary science, Chulalongkorn university. A total of 14 samples were collected from the wound abscess of 14 dogs in surgery, post-surgery care, and the dermatological room on the same day as the staff and environmental samplings. Outpatient dogs with wound infection or dermatitis were chosen from each clinical room with the authorisation of the owner's veterinarian and permission. The moist, sterile cotton swabs were dipped in $2 \mathrm{~mL}$ of PSD into a sterile test tube [18], then rolled on the wound sites of dogs, and treated as above.

\section{Identification of COPS and MRCoPS}

Samples were cultured within $2 \mathrm{~h}$ of the collection in an enrichment culture. A total of $0.1 \mathrm{~mL}$ of the suspension was spread on Baird-Parker agar (Difco ${ }^{\mathrm{TM}}$, France) without and with $0.5 \mu \mathrm{g} / \mathrm{mL}$ oxacillin (screening plate) Staphylococci selection. After incubation at $35^{\circ} \mathrm{C}$ for $48 \mathrm{~h}$, black Staphylococci-like colonies were selected. Three presumptive Staphylococci colonies were purified on tryptic soy agar (TSA; Difco ${ }^{\mathrm{TM}}$, France) and confirmed with the coagulase test. All CoPS were identified by primary and secondary biochemical tests, as previously reported [33]. Multiplex-PCR (M-PCR) and matrix-assisted laser desorption/ionisation-time of flight mass spectrometry (MALDI-TOF) were used for characterisation as previously reported [34, 35], where $S$. aureus ATCC 25923, S. pseudintermedius CVMC 0108, S. schleiferi subsp. coagulans CVMC 0208 (canine origin), S. intermedius CVMP 0309, and S. delphini CVMP 0109 were used as control strains. All CoPS were screened using the oxacillin disk diffusion method. The oxacillin $(1 \mu \mathrm{g})$ and cefoxitin $(30 \mu \mathrm{g})$ breakpoints were used to confirm MRCoPS, as defined by the CLSI recommendation [36]. All 
oxacillin-resistant isolates were characterised as MRCoPS and approved by the presence of the mecA gene by M-PCR as reported [37], and using S. aureus ATCC 25923 and MRSA N315 as the internal control strains.

\section{Antibiogram, SCCmectyping, and clone typing of the CoPS and MRCoPS isolates}

All MRCoPS strains were further determined for their antibiograms and SCCmec types by the disk diffusion method [36] with clindamycin (DA; $2 \mu \mathrm{g})$, doxycycline (DO; $30 \mu \mathrm{g})$, gentamicin (CN; $10 \mu \mathrm{g})$, erythromycin (E; $15 \mu \mathrm{g})$, mupirocin (MUP; $200 \mu \mathrm{g}$ ), and sulfamethoxazole/trimethoprim (SXT; $25 \mu \mathrm{g})$, and using S. aureus ATCC 25923 as the control strain. The susceptibility level was interpreted following the Clinical and Laboratory Standards Institute (CLSI) recommendation [2013], while the determination of the DO breakpoint followed that of Maaland [38]. In addition, the breakpoint of amoxicillin/clavulanic acid is not presented in this edition of CLSI [2013].

The conserved fragments of the mec gene complex and ccrgene complex were detected by M-PCR to identify the SCCmec type [39]. To determine the clonal relationship between CoPS and MRCoPS, pulsed-field gel electrophoresis (PFGE) was performed as recommended [18]. Briefly, bacterial DNA was plugged into Seakem ${ }^{\circledR}$ agarose (Bio-Rad, USA) and cut with the Cfr9/enzyme. In the case of uncut samples, Apa/ was used as the restriction enzyme [8]. The DNA fragments were then separated on a CHEFIII at $6 \mathrm{~V} / \mathrm{cm}, 14^{\circ} \mathrm{C}, 120^{\circ}$ in a $1 \%(\mathrm{w} / \mathrm{v})$ pulsed-field grade agarose gel with switching at 5-15 s for $18 \mathrm{~h}$ and $15-60 \mathrm{~s}$ for $5 \mathrm{~h}$. Gels were stained with red safe ${ }^{\mathrm{TM}}$ Nucleic Acid Staining Solution (Scientific, NSW, AUS), destained in water, and then digitally captured under UV light [40]. The Lambda Ladder PFG Marker (New England BioLabs, Beverly, Mass) was used as the size ladder. The Bionumeric program associated with the dice coefficient [1.5] was used for dendrogram construction (UPGMA with 1.0\% position tolerance). Individual patterns were discriminated based on $80 \%$ similarity.

\section{Data analysis}

Statistic 22 for Microsoft Windows (SPSS Inc.; Chicago, IL, USA) was used for statistical analysis. The prevalence of CoPS, MRCoPS, and MSCoPS positive surfaces are described as a percentile, while the odds ratio (OR) explained the risk factor in each room compared to the reference room, which was chosen as the room with the lowest level of MRCoPS-positive surfaces.

\section{Declarations}

\section{Abbreviations}

CoPS: Coagulase-positive staphylococci; MR: methicillin-resistant; MRCoPS: Methicillin-resistant coagulase-positive staphylococci; VTH: Veterinary Teaching Hospital; CU: Chulalongkorn University; SCCmec: Staphylococcal chromosomal cassette mec, PFGE: Pulsed-field gel electrophoresis; MRSP: methicillin-resistant Staphylococcus pseudointermedius; MRSSc: methicillin-resistant Staphylococcus schleiferi subsp. coagulans, MRSA: methicillinresistant S. aureus; MS: methicillin-susceptible; MSSA: methicillin-susceptible S. aureus; MSCoPS: methicillinsusceptible coagulase-positive staphylococci; DA: clindamycin; E: erythromycin; MUP: mupirocin; M: general medicine; V: vaccination room; G: gynaecology; SW: dermatology; S: surgery; P: post-surgery care; ICU: intensive care unit; H: hallway; ICU: intensive care unit; PSD: peptone saline diluent; CN: gentamycin; SXT: sulfamethoxazole/trimethoprim; CLSI: Clinical and Laboratory Standards Institute; DO: doxycycline

\section{References}




\section{Ethics approval and consent to participate}

Study was approved by Institutional Animal Care and Use Committee (113/56), Faculty of veterinary science, Chulalongkorn university and the Ethical Review Committee for Research Involving Human Research Subjects, Health Science Group, CU (137/57), Research and innovation for society, Chulalongkorn University. Before this experiment started sample collection, the written informed consent was obtained from participants and dog owners.

\section{Consent for publication}

Not applicable.

\section{Availability of data and materials}

The datasets used and/or analysed during the current study are available from the corresponding author on reasonable request.

\section{Competing interests}

The authors declare that they have non-financial competing interests.

\section{Funding}

This research supported by an overseas Research Experience Scholarship for Graduate Student, from Chulalongkorn University. The funding had role in data analysis, interpretation of data and writing the manuscript.

\section{Author's contributions}

PF was responsible for designing the study, sampling, isolation, characterisation of the various bacterial isolates, PFGE, data analysis and drafted the manuscript. JM analysed results from MALDI-TOF MS and approved the manuscript. NP conceptualised and approved the manuscript. All authors read and approved the final manuscript.

\section{Acknowledgements}

We thank the Institute for Animal Hygiene and Environmental Health, Department of Veterinary Medicine and the Institute of Microbiology and Epizootics, Free University of Berlin, Berlin, Germany for research experience. We sincerely thank you Dr. Birgit Walther for analysing PFGE data. We finally thank Research Clinic Unit, Office of Research Affairs, Chulalongkorn University, to provide editorial assistance during the preparation of this manuscript.

\section{Tables}

Table 1 The criteria of sample collection on floors and medical instruments 


\begin{tabular}{|c|c|c|c|}
\hline $\begin{array}{l}\text { Environmental } \\
\text { samples }\end{array}$ & Type & Sample/room/time & Criteria (area per swab) \\
\hline Floor & Floor & 5 & $\begin{array}{l}3 \times 3 \mathrm{~cm}^{2} \text { from five parts; right up, right down, } \\
\text { middle, left up and left down in the main } \\
\text { examination room }\end{array}$ \\
\hline \multirow[t]{9}{*}{$\begin{array}{l}\text { Medical } \\
\text { instruments }\end{array}$} & Cotton & 1 & $\begin{array}{l}\text { One gram of bandaging wound cotton in the main } \\
\text { examination room }\end{array}$ \\
\hline & Stethoscope & 1 & $\begin{array}{l}0.1 \times 0.1 \mathrm{~cm}^{2} \text { of animal contact surface of } \\
\text { stethoscopes in the main examination room }\end{array}$ \\
\hline & $\begin{array}{l}\text { Syringe } \\
\text { plate }\end{array}$ & 1 & $\begin{array}{l}0.1 \times 0.1 \mathrm{~cm}^{2} \text { of syringe plate in the in the main } \\
\text { examination room }\end{array}$ \\
\hline & $\begin{array}{l}\text { Disinfectant } \\
\text { water }^{[1]}\end{array}$ & 1 & $\begin{array}{l}1 \mathrm{~mL} \text { of disinfectant water in forceps jar in the main } \\
\text { examination room }\end{array}$ \\
\hline & $\begin{array}{l}\text { Examination } \\
\text { table }\end{array}$ & 1 & $\begin{array}{l}10 \times 10 \mathrm{~cm}^{2} \text { on the surfaces of examination table in } \\
\text { the main examination room }\end{array}$ \\
\hline & $\begin{array}{l}\text { Waiting } \\
\text { branch }\end{array}$ & 1 & $\begin{array}{l}10 \times 10 \mathrm{~cm}^{2} \text { waiting branch in front of the main } \\
\text { examination rooms }\end{array}$ \\
\hline & $\begin{array}{l}\text { Drug } \\
\text { cabinet }\end{array}$ & 1 & $10 \times 10 \mathrm{~cm}^{2}$ of drug cabinet in Division or unit \\
\hline & Keyboard & 1 & $\begin{array}{l}10 x 10 \mathrm{~cm}^{2} \text { of keyboard in the main examination } \\
\text { room }\end{array}$ \\
\hline & Knot door & 1 & $\begin{array}{l}0.1 \times 0.1 \mathrm{~cm}^{2} \text { of knot door on the front door in the } \\
\text { main examination }\end{array}$ \\
\hline
\end{tabular}

Table 2 Distribution of MSCoPS and MRCoPS on floor and medical instruments 


\begin{tabular}{|c|c|c|c|c|c|c|}
\hline Unit & Floor & Examination table & Syringe plate & Keyboard & Un-used cotton & Knot door \\
\hline Gynecology & $\mathrm{r}$ & $\mathrm{rp}$ & & & $\mathrm{r} \square$ & \\
\hline Internal Medicine & $\mathrm{rp} \square$ & & $\mathrm{rp}$ & प & & \\
\hline Post- surgery care & $\mathrm{r}$ & $\mathrm{r}$ & & $\mathrm{rp}$ & & $\mathrm{r}$ \\
\hline Surgery & & $\mathrm{p}$ & & & & \\
\hline Dermatological & $\mathrm{r}$ & $\mathrm{r}$ & $\mathrm{r}$ & & & $\mathrm{r}$ \\
\hline Vaccine & $\mathrm{p}$ & & & & & \\
\hline ICU & $\mathrm{p}$ & $\square$ & & & & \\
\hline Hall Ways & $\mathrm{p} \square$ & & & & & \\
\hline
\end{tabular}

Grey $=$ non detectable

$\mathrm{p}=$ methicillin-susceptible $S$. pseudintermedius (MSSP)

$\mathrm{r}=$ methicillin-resistant $S$. pseudintermedius (MRSP)

$\square=$ methicillin-susceptible $S$. schleiferi subsp. coagulans (MSSSc)

$\square=$ methicillin-resistant $S$. schleiferi subsp. coagulans (MRSSc)

Table 3 Distribution, main antibiotic use, routine cleaning, positive surface and odd ratio of MRCoPS 


\begin{tabular}{|c|c|c|c|c|c|c|}
\hline \multirow[t]{2}{*}{ Places } & \multirow[t]{2}{*}{ Main antibiotic used } & \multirow{2}{*}{$\begin{array}{l}\text { Routine Cleaning } \\
\text { management (antiseptic/equipment/time) }\end{array}$} & \multicolumn{2}{|c|}{ Floor } & \multicolumn{2}{|c|}{ Medical Instrument ${ }^{a}$} \\
\hline & & & $\begin{array}{c}\text { MRCoPS } \\
\text { positive } \\
\text { surfaces (\%) }\end{array}$ & $\begin{array}{l}\text { Odd ratio } \\
\text { of } \\
\text { MRCoPS } \\
\text { positive } \\
\text { surfaces }\end{array}$ & $\begin{array}{c}\text { MRCoPS } \\
\text { positive } \\
\text { surfaces (\%) }\end{array}$ & $\begin{array}{l}\text { Odd ratio } \\
\text { of } \\
\text { MRCoPS } \\
\text { positive } \\
\text { surfaces }\end{array}$ \\
\hline Gynecology & Enrofloxacin & $\begin{array}{l}2.5 \% \text { quaternary ammonium } \\
\text { compound/Mob/1 }\end{array}$ & $5 / 10(50 \%)$ & 4 & $2 / 18(11.11 \%)$ & 2.15 \\
\hline Medicine & $\begin{array}{l}\text { Amoxicillin/clavulanic } \\
\text { acid }\end{array}$ & $\begin{array}{l}2.5 \% \text { quaternary ammonium } \\
\text { compound/Mob/1 }\end{array}$ & $2 / 10(20 \%)$ & Reference & $1 / 18$ (5.56\%) & Reference \\
\hline $\begin{array}{l}\text { Post- surgery } \\
\text { care }\end{array}$ & Enrofloxacin & $\begin{array}{l}2.5 \% \text { quaternary ammonium } \\
\text { compound/Mob/2 }\end{array}$ & $3 / 10(30 \%)$ & 1.71 & $3 / 18(16.67 \%)$ & 3.45 \\
\hline Surgery & Enrofloxacin & $\begin{array}{l}2.5 \% \text { quaternary ammonium } \\
\text { compound/Mob/1 }\end{array}$ & $0 / 10(0 \%)$ & $\mathrm{N} / \mathrm{A}$ & $1 / 18(5.6 \%)$ & 1 \\
\hline Dermatological & $\begin{array}{l}\text { Amoxicillin/clavulanic } \\
\text { acid, Cephalexin and } \\
\text { Metronidazole }\end{array}$ & No antiseptic/Broom/1 & $6 / 10(60 \%)$ & 6 & $3 / 18$ (16.67\%) & 3.45 \\
\hline Vaccine & $\begin{array}{l}\text { No Antibiotic drug } \\
\text { used }\end{array}$ & $\begin{array}{l}2.5 \% \text { quaternary ammonium } \\
\text { compound/Mob/1 }\end{array}$ & $0 / 10(0 \%)$ & $\mathrm{N} / \mathrm{A}$ & $0 / 18(0 \%)$ & $\mathrm{N} / \mathrm{A}$ \\
\hline ICU & $\begin{array}{l}\text { Amoxicillin/clavulanic } \\
\text { acid, Cephalexin and } \\
\text { Metronidazole }\end{array}$ & $\begin{array}{l}2.5 \% \text { quaternary ammonium } \\
\text { compound/Mob/2 }\end{array}$ & $0 / 10(0 \%)$ & $\mathrm{N} / \mathrm{A}$ & $1 / 18(5.6 \%)$ & 1 \\
\hline Hall way ${ }^{b}$ & $\begin{array}{l}\text { No Antibiotic drug } \\
\text { used }\end{array}$ & Unknown/Mob/1 & $0 / 10(0 \%)$ & $\mathrm{N} / \mathrm{A}$ & & \\
\hline
\end{tabular}

a Medical instrument $=$ cotton, stethoscope, disinfectant water, syringe plate, examination table, waiting branch, drug cabinet, keyboard and knot door

$\mathrm{b}_{\text {Hall way have no medical instrument detection }}$

${ }^{[1]}$ Negative control 


\section{Figures}

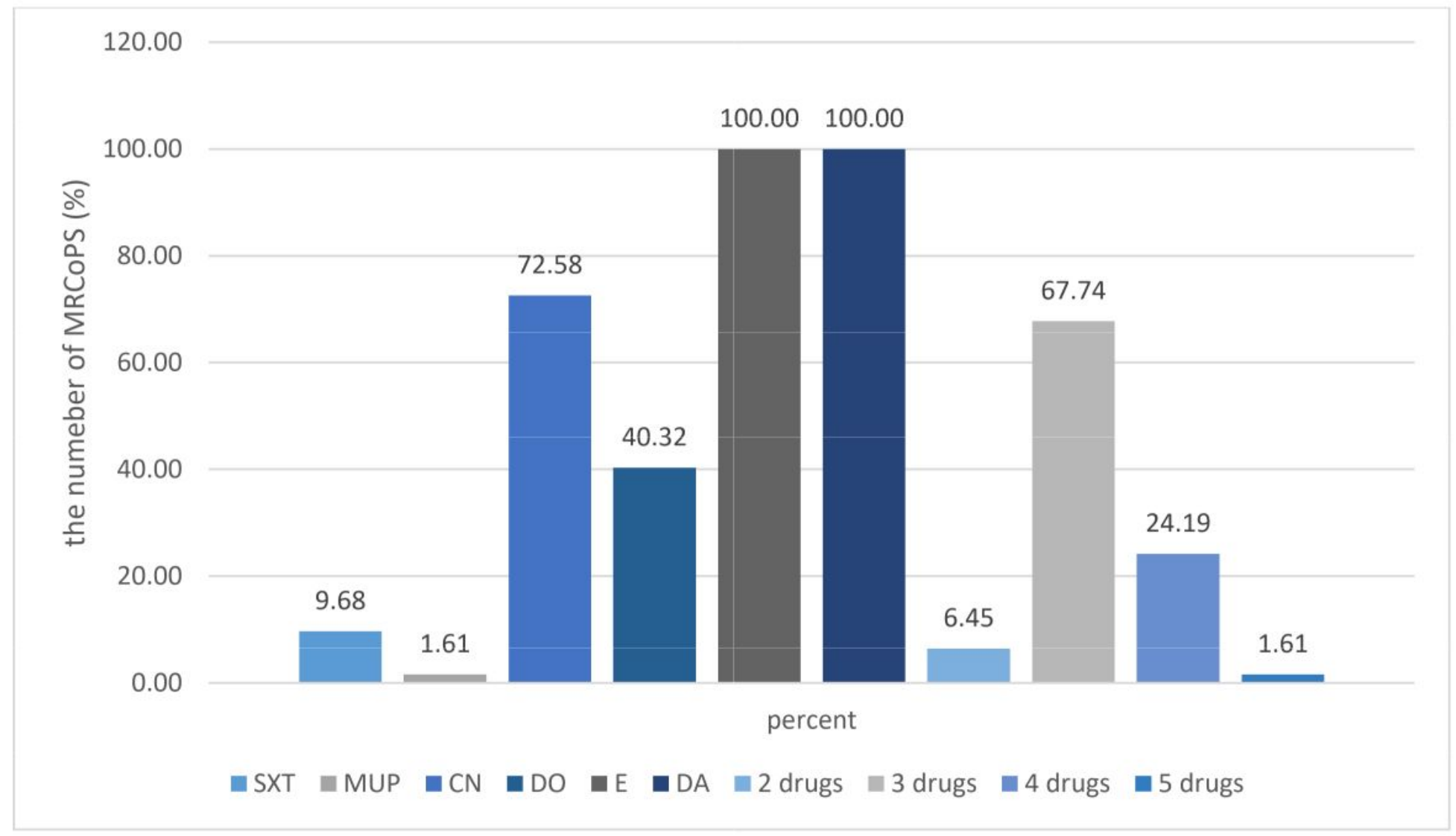

Figure 1

Percentile of resistant antibiotic drugs. This figure showed resistant antibiotic drugs and included combine resisting 3 antibiotic drugs, 4 antibiotic drugs and 5 antibiotic drugs. 

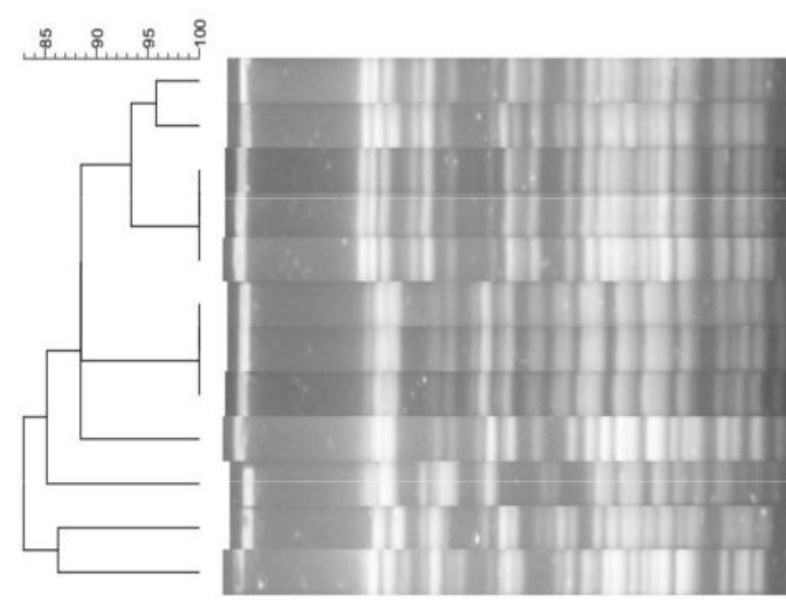

\begin{tabular}{lccll}
\hline Original & IMT & Ward & Origin/Room & mec $A$ \\
C2TB1 & 34905 & ICU & Table \\
G1CB2 & 34907 & G & Un-used cotton & \\
M2F1B1 & 34940 & IM & Floor \\
M2F1B2 & 34941 & IM & Floor \\
M2F1B3 & 34942 & IM & Floor \\
L2F1B1 & 34932 & H & Floor \\
L2F1B2 & 34933 & H & Floor \\
L2F1B3 & 34934 & H & Floor \\
M2KB1 & 34946 & IM & Keyboard \\
C2F1B1 & 34903 & ICU & Floor \\
C2F3B1 & 34904 & ICU & Floor \\
M2KB3 & 34947 & IM & Keyboard & \\
\hline
\end{tabular}

gene
+

$+$

$+$

$+$

$+$

$+$

$-$

-

$-$

-

$-$
SCCmec untypeable

untypeable

untypeable

untypeable

untypeable

N/A

N/A

N/A

N/A

N/A

N/A

N/A
PFGE Pattern

A

A

A

A

A

A

A

A

A

A

B

B

\section{Figure 2}

S. schleiferi subsp. coagulans cutting with cfr9I. This figure showed the SCCmec type and pattern of pulsed-field gel electrophoresis (PFGE) of S. schleiferi subsp. coagulans from many sources in the Small Animal Teaching Hospital. 


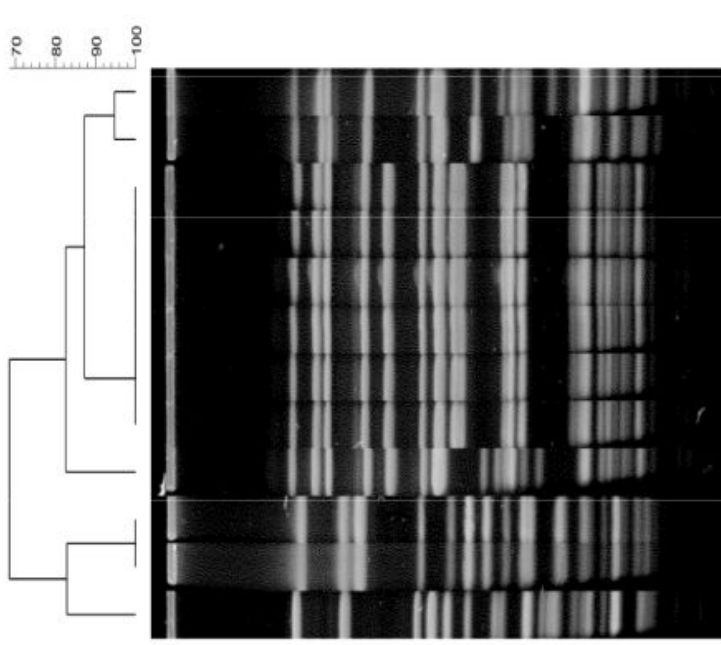

$\begin{array}{lccl}\text { Original } & \text { IMT } & \text { Ward } & \text { Origin/Room } \\ \text { G2F3B1 } & 34925 & \text { G } & \text { Floor } \\ \text { P1F2B1 } & 34949 & \text { P } & \text { Floor } \\ \text { G1TB1 } & 34919 & \text { G } & \text { Table } \\ \text { G1TB2 } & 34920 & \text { G } & \text { Table } \\ \text { G1TB3 } & 34921 & \text { G } & \text { Table } \\ \text { G1TO1 } & 34922 & \text { G } & \text { Table } \\ \text { G1TO2 } & 34923 & \text { G } & \text { Table } \\ \text { G1TO3 } & 34924 & \text { G } & \text { Table } \\ \text { G2F5B1 } & 34926 & \text { G } & \text { Floor } \\ \text { P1F4B1 } & 34950 & \text { P } & \text { Floor } \\ \text { P1F4B2 } & 34951 & \text { P } & \text { Floor } \\ \text { M2PB3 } & 34948 & \text { IM } & \text { Plates }\end{array}$

mecA
gene
+
+
+
+
+
+
+
+
+
+
+
+
+

sCCmec

untypeable

5

untypeable

untypeable

untypeable

untypeable

untypeable

untypeable

untypeable

5

5

N/A
PFGE

Pattern

A

A

A

A

A

A

A

A

A

B

B

C

\section{Figure 3}

S. pseudintermedius cutting with Apal. This figure showed the SCCmec type and pattern of pulsed-field gel electrophoresis (PFGE) of S. pseudintermedius from many sources in the Small Animal Teaching Hospital. 


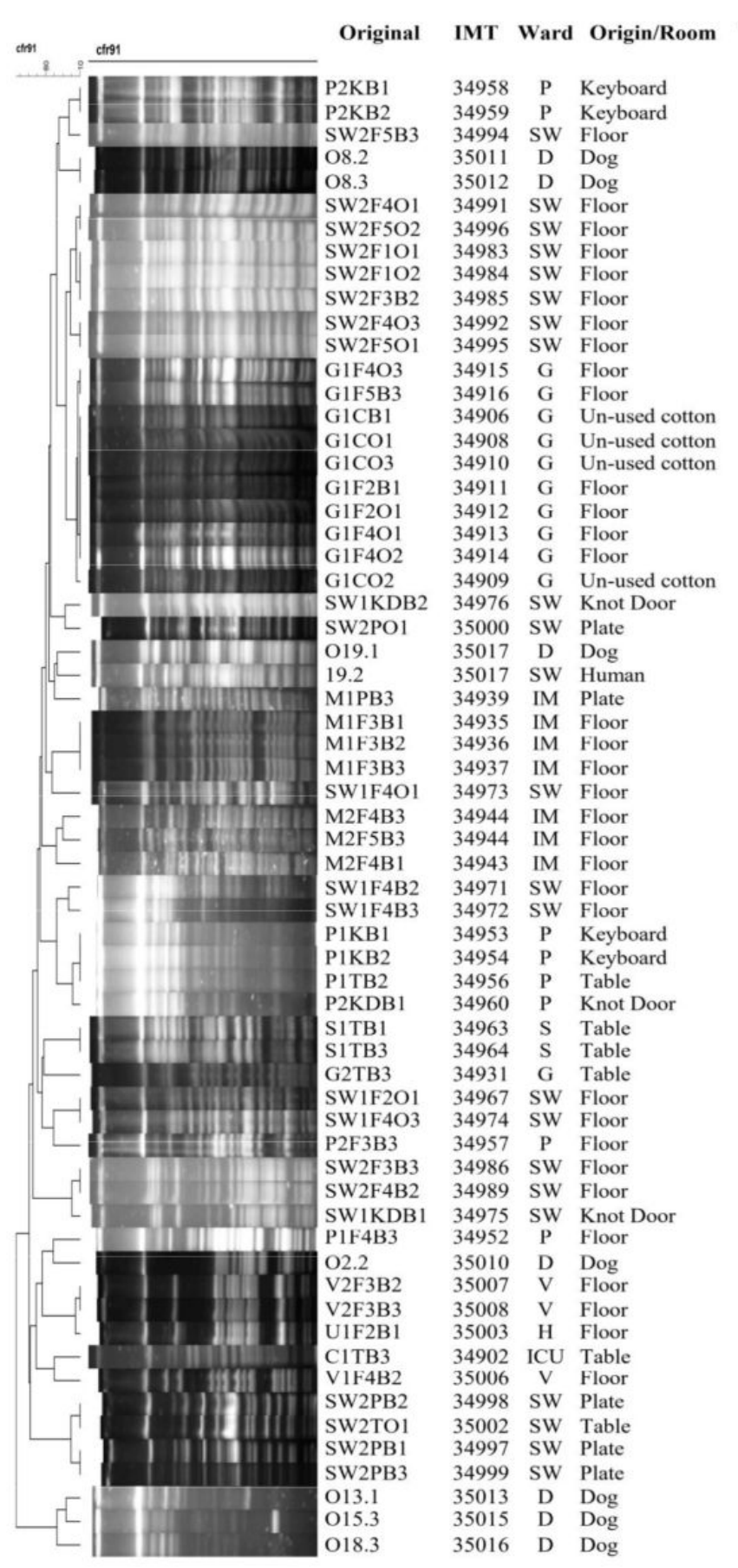

\begin{tabular}{|c|c|c|}
\hline $\begin{array}{c}\text { mecA } \\
\text { gene }\end{array}$ & SCCmec & $\begin{array}{c}\text { PFGE } \\
\text { Pattern }\end{array}$ \\
\hline - & N/A & A \\
\hline - & N/A & A \\
\hline+ & untypeable & A \\
\hline+ & untypeable & A \\
\hline+ & untypeable & A \\
\hline+ & untypeable & A \\
\hline+ & untypeable & A \\
\hline+ & untypeable & A \\
\hline+ & untypeable & A \\
\hline+ & untypeable & A \\
\hline+ & untypeable & A \\
\hline+ & untypeable & A \\
\hline+ & untypeable & A \\
\hline+ & untypeable & A \\
\hline+ & untypeable & A \\
\hline+ & untypeable & A \\
\hline+ & untypeable & A \\
\hline+ & untypeable & A \\
\hline+ & untypeable & A \\
\hline+ & untypeable & A \\
\hline+ & untypeable & A \\
\hline+ & untypeable & A \\
\hline+ & untypeable & A \\
\hline+ & untypeable & A \\
\hline+ & 5 & B \\
\hline+ & 5 & $\mathrm{C}$ \\
\hline+ & untypeable & D \\
\hline- & N/A & $\mathrm{E}$ \\
\hline- & $\mathrm{N} / \mathrm{A}$ & E \\
\hline- & N/A & $\mathrm{E}$ \\
\hline+ & untypeable & $\mathrm{E}$ \\
\hline- & N/A & $\mathrm{F}$ \\
\hline+ & untypeable & $\mathrm{F}$ \\
\hline- & N/A & $\mathrm{F}$ \\
\hline+ & untypeable & G \\
\hline+ & untypeable & G \\
\hline+ & 5 & G \\
\hline+ & 5 & G \\
\hline+ & 5 & G \\
\hline+ & 5 & G \\
\hline- & N/A & $\mathrm{H}$ \\
\hline- & N/A & $\mathrm{H}$ \\
\hline- & $\mathrm{N} / \mathrm{A}$ & $\mathrm{H}$ \\
\hline+ & 5 & $\mathrm{H}$ \\
\hline+ & untypeable & $\mathrm{H}$ \\
\hline+ & 5 & $\mathrm{H}$ \\
\hline+ & untypeable & I \\
\hline+ & untypeable & I \\
\hline+ & untypeable & I \\
\hline+ & 5 & J \\
\hline+ & 5 & $\mathbf{J}$ \\
\hline- & N/A & $\mathbf{J}$ \\
\hline - & N/A & $\mathbf{J}$ \\
\hline- & N/A & $\mathbf{J}$ \\
\hline- & $\mathrm{N} / \mathrm{A}$ & K \\
\hline- & N/A & $\mathrm{L}$ \\
\hline+ & untypeable & M \\
\hline+ & untypeable & M \\
\hline+ & untypeable & M \\
\hline+ & untypeable & M \\
\hline- & N/A & $\mathrm{N}$ \\
\hline+ & untypeable & $\mathrm{N}$ \\
\hline- & N/A & $\mathrm{N}$ \\
\hline
\end{tabular}

\section{Figure 4}

S. pseudintermedius cutting with cfr9I. This figure showed the SCCmec type and pattern of pulsed-field gel electrophoresis (PFGE) of S. pseudintermedius from many sources in the Small Animal Teaching Hospital. 